\title{
Description of a strain from an atypical population of Aspergillus parasiticus that produces aflatoxins B only, and the impact of temperature on fungal growth and mycotoxin production
}

\author{
Arita C • Calado T • Venâncio A • Lima N • \\ Rodrigues $\mathbf{P}$
}

Accepted: 23 April 2014 /Published online: 29 April 2014

(C) Koninklijke Nederlandse Planteziektenkundige Vereniging 2014

\begin{abstract}
In this study, an atypical strain of Aspergillus parasiticus is described. This strain, reported from Portuguese almonds, was named Aspergillus parasiticus B strain. The strain is herein characterised at the morphological and physiological levels, and compared with the typical $A$. parasiticus strain and other similar species in section Flavi. Previously published morphological and molecular data support that the B strain is very closely related to the $A$. parasiticus type strain. However, while A. parasiticus typically produces aflatoxins $\mathrm{B}$ and $\mathrm{G}, \mathrm{B}$ strain produces aflatoxins B only. Furthermore, this atypical strain showed to differ from the typical strain in the fact that higher growth (colony diameter) and aflatoxin $\mathrm{B} 1$ production were observed at $25^{\circ} \mathrm{C}$ than at $30^{\circ} \mathrm{C}$, whereas the opposite was observed for the typical strain. This strain can become a major food safety concern in colder regions where the typical A. parasiticus strains are not well adapted.
\end{abstract}

A. C $\cdot$ R. P $(\bowtie)$

CIMO/School of Agriculture of the Polytechnic Institute of Bragança, Campus de Santa Apolónia, 5301-855 Bragança, Portugal

e-mail: prodrigues@ipb.pt

A. C

Universidade Federal da Viçosa, Campus de Viçosa, Avenida Peter Henry Rolfs, s/n 36570-000 MG, Brazil

C. T $\cdot$ V. A $\cdot$ L. N

CEB-Centre of Biological Engineering, University of Minho, Braga, Portugal
Keywords Fungal ecology · Food mycology

Mycotoxins $\cdot$ Aflatoxins $\cdot$ Cyclopiazonic acid

Aspergillus flavus and Aspergillus parasiticus remain the most important and representative species of Aspergillus section Flavi occurring naturally in food commodities. These species are responsible for the production of aflatoxins in a wide variety of foods all over the world. Aflatoxins are highly toxic secondary metabolites and aflatoxin B1 (AFB1) is regarded as the most potent naturally occurring carcinogen (Bennett and Klich 2003). Given the relevance of aflatoxins in food and feeds, considerable interest has been put in the intraspecific toxigenic variability of $A$. flavus and $A$. parasiticus. While $A$. flavus populations have generally been found to be extremely diverse in terms of toxigenicity, $A$. parasiticus strains are more uniform in their toxigenic abilities: they are usually strongly aflatoxigenic, producing both AFBs and AFGs, and do not produce cyclopiazonic acid (CPA), a mycotoxin that is commonly used to differentiate species belonging to section Flavi. Non-aflatoxigenic strains seem to be extremely rare (Blaney et al. 1989; Doster et al. 1996; Horn et al. 1996; McAlpin et al. 1998; Tran-Dinh et al. 1999; Vaamonde et al. 2003).

Aspergillus parasiticus is apparently less widespread in nature than A.flavus, and it seems to be more adapted to survival in the soil and less dependent on crop infection (Horn 2007). As a matter of fact, this species is generally isolated quite rarely from the majority of foods 
and was reported to be important only in soils and underground foods like peanuts (Horn 2005; Klich 2002; Vaamonde et al. 2003). Also, it has been stated to be geographically restricted to USA, South America and Australia (Frisvad et al. 2006), but our group has reported unusually high proportions of $A$. parasiticus contaminating Portuguese almonds (48\% of all Aspergillus section Flavi isolates) (Rodrigues et al., 2009, 2011). For many years, researchers did not separate A. flavus from $A$. parasiticus in field studies, which led to some confusion regarding their distribution. Even today, as new species are constantly being described, some doubts remain on the true identification of some isolates that phenotypically resemble the most common species. As a consequence, biodiversity and biogeography of aflatoxigenic species need to be regarded with caution. In fact, with the development of more complete and sensitive schemes of identification, three new aflatoxigenic species closely related to A parasiticus have been recently described from foods: A. arachidicola (Pildain et al. 2008), A. transmontanensis (Soares et al. 2012) and A. sergii (Soares et al. 2012). Aspergillus nomius is also strongly aflatoxigenic, having an aflatoxigenic profile similar to A. parasiticus (Kurtzman et al. 1987).

Geographical differences and differences in isolates from ecological niches have been largely described for A. flavus (Cotty and Cardwell 1999; Klich and Pitt
1988), but not for $A$. parasiticus. In a survey conducted by our group on Aspergillus section Flavi from Portuguese almonds, one group of nine isolates was obtained which morphologically resembled $A$. parasiticus, but showed an extrolite profile (in terms of AFs and CPA) different from both A. parasiticus and A. flavus (Rodrigues et al. 2011). While typical A. parasiticus isolates produced both AFBs and AFGs, these isolates produced AFBs only, thus resembling A. flavus. On the other hand, CPA production ability was not detected in these isolates, which resembles typical A. parasiticus. Despite this unusual mycotoxigenic pattern, the detailed comparison of these isolates with other section Flavi type-strains in terms of sequence analysis of partial calmodulin gene as well as protein spectral analysis by MALDI-TOF ICMS grouped these isolates with the typical A. parasiticus strains (Rodrigues et al. 2011).

In the present study, we aimed to further analyse this atypical group of isolates at the morphological and physiological levels, and compare its ability to grow and produce mycotoxins under different conditions with the typical $A$. parasiticus and other closely related species in section Flavi.

The isolates of Aspergillus section Flavi used in this study are listed in Table 1 . Isolates were maintained in $20 \%$ glycerol at $-20^{\circ} \mathrm{C}$ and grown on Malt Extract Agar (MEA: Malt $20 \mathrm{~g} \mathrm{l}^{-1}$, Glucose $20 \mathrm{~g} \mathrm{l}^{-1}$, Peptone $1 \mathrm{~g}^{-1}$, Agar $20 \mathrm{~g} \mathrm{l}^{-1}$ ) in the dark for $7 \mathrm{~d}$ at $25^{\circ} \mathrm{C}$ whenever

Table 1 Isolates of Aspergillus section Flavi used in this study ( ${ }^{\mathrm{T}}$ refers to type-strains)

\begin{tabular}{|c|c|c|c|}
\hline Strain number & Source & GenBank accession number Calmodulin & Species name \\
\hline MUM $10.238^{\mathrm{T}}(\mathrm{CBS} 117610)$ & Arachis glabrata leaf; Argentina & EF202049 & A. arachidicola \\
\hline MUM $10.237^{\mathrm{T}}(\mathrm{CBS} 100927)$ & Cellophane; South pacific Islands & EF202063 & A. flavus \\
\hline MUM $10.241^{\mathrm{T}}(\mathrm{CBS} 100928)$ & Soy sauce; Japan & EF202041 & A. sojae \\
\hline MUM 92.02 (NRRL 3386) & & HQ340099 & A. parasiticus \\
\hline MUM $10.214^{\mathrm{T}}$ (09AAsp260) & Prunus dulcis nut; Portugal & HQ340092 & A. transmontanensis \\
\hline MUM $10.219^{\mathrm{T}}$ (09AAsp494) & Prunus dulcis nut; Portugal & HQ340097 & A. sergii \\
\hline MUM 09.02 (NRRL 13137) & Wheat, USA & EF202028 & A. nomius \\
\hline 08AAsp158 & Prunus dulcis nut; Portugal & & A. parasiticus $\mathrm{B}$ strain \\
\hline MUM 10.212 (09AAsp187) & Prunus dulcis nut; Portugal & HQ340090 & A. parasiticus $\mathrm{B}$ strain \\
\hline 09AAsp232 & Prunus dulcis nut; Portugal & & A. parasiticus $\mathrm{B}$ strain \\
\hline MUM 10.224 (09AAsp235) & Prunus dulcis nut; Portugal & & A. parasiticus B strain \\
\hline MUM 10.256 (09Aasp241) & Prunus dulcis nut; Portugal & JF500459 & A. parasiticus $\mathrm{B}$ strain \\
\hline MUM 10.257 (09Aasp246) & Prunus dulcis nut; Portugal & JF500460 & A. parasiticus $\mathrm{B}$ strain \\
\hline 09AAsp539 & Prunus dulcis nut; Portugal & & A. parasiticus $\mathrm{B}$ strain \\
\hline
\end{tabular}


needed for further studies. All isolates listed were submitted to morphological and physiological analysis. For each isolate, a loop full of spores of $7 \mathrm{~d}$-old cultures on MEA was suspended in $500 \mu \mathrm{l}$ of $0.2 \%$ agar, and this suspension was used for three-point inoculations on $9 \mathrm{~cm}$ diameter Petri dishes containing $20 \mathrm{ml}$ of: MEA, Czapek Yeast Autolysate (CYA) and CY20S (as described by Klich 2002), Aspergillus flavus and A. parasiticus agar (AFPA; Oxoid, Basingstoke, United Kingdom) and YES (Yeast Extract $20 \mathrm{~g} \mathrm{l}^{-1}$, Sucrose $150 \mathrm{~g} \mathrm{l}^{-1}$, Agar $15 \mathrm{~g} \mathrm{l}^{-1}$ ). Cultures were incubated for 7 $\mathrm{d}$, in the dark, at $5,15,25,30,37$ and $42^{\circ} \mathrm{C}$, and then analysed for colony colour and diameter on the various media, as well as presence and size of sclerotia. The following micromorphological features were analysed in MEA at $25^{\circ} \mathrm{C}$ : conidia size and ornamentation, head seriation, vesicle diameter, and size of metulae and phialide. Morphological identification followed the taxonomic keys and guides available for the Aspergillus genus (Klich 2002; Samson et al. 2004).

All strains were tested for aflatoxin production in aflatoxin-inducing Yeast Extract Sucrose (YES) medium. Strains were inoculated on $9 \mathrm{~cm}$ diameter plates (in triplicate) and incubated at 25,30 and $37^{\circ} \mathrm{C}$ for 7 days, in the dark. Then the methodology of Bragulat et al. (2001) was employed: 3 agar plugs were removed from each plate, weighted and placed into a $4 \mathrm{ml}$ vial, where $1 \mathrm{ml}$ of methanol was added. After $60 \mathrm{~min}$, the extract was filtered by $0.45 \mu \mathrm{m}$ filters. Samples were analysed using a HPLC equiped with a Jasco FP-920 fluorescence detector (365 nm exCitation wavelength; $435 \mathrm{~nm}$ emission wavelength), using a photochemical postcolumn derivatization reactor (PHRED unit - Aura Industries, USA). Chromatographic separations were performed on a reverse phase C18 column (Waters Spherisorb ODS2, $4.6 \mathrm{~mm} \times 250 \mathrm{~mm}, 5 \mu \mathrm{m}$ ), fitted with a precolumn with the same stationary phase. The mobile phase used was pumped at $1.0 \mathrm{ml} / \mathrm{min}$ and consisted of an isocratic programme as follows: water: acetonitrile: methanol (3:1:1, v/v). The injection volume was $20 \mu \mathrm{l}$. Aflatoxins standard was supplied by Biopure (Austria). A mix of aflatoxins, containing $2 \mu \mathrm{g} / \mathrm{ml}$ each of AFB1 and AFG1, and $0.5 \mu \mathrm{g} / \mathrm{ml}$ each of AFB2 and AFG2 was used.

Linearity, limit of detection (LOD) and limit of quantification (LOQ) were determined by two series of analyses, using five standard solutions of AFB1 and AFG1 each at concentrations of 200,100,50, 20 and $1 \mathrm{ng} \mathrm{ml}^{-1}$, and AFB2 and AFG2 each at concentrations of $60,30,15$, 6 and $0.3 \mathrm{ng} \mathrm{ml}^{-1}$. Each standard solution was analysed in triplicate. LOD and LOQ were calculated according to the following equations (Taverniers et al. 2004): $\mathrm{LOD}=3 \mathrm{sa} / \mathrm{b}$ and $\mathrm{LOQ}=10 \mathrm{sa} / \mathrm{b}$, where $s a$ is the standard deviation of the intercept of the regression line obtained from the calibration curve and $b$ is the slope of the line.

Since CPA production ability is a distinctive feature in section Flavi, the strains were also tested for CPA in CYA medium. All strains were inoculated on $6 \mathrm{~cm}$ diameter plates and incubated at $25{ }^{\circ} \mathrm{C}$ for 14 days, in the dark (Gqaleni et al. 1997). Then the methodology of Bragulat et al. (2001) was employed, as already described for aflatoxin analysis. Samples were analysed using a HPLC equiped with a Varian 2050 UV detector (285 nm). Chromatographic separations were performed on a EuroSpher $100 \mathrm{NH}_{2}$ column (Knauer, $4.6 \mathrm{~mm} \times 250 \mathrm{~mm}, 5 \mu \mathrm{m}$ ), fitted with a precolumn with the same stationary phase. The mobile phase used was pumped at $1.0 \mathrm{ml} \mathrm{min}^{-1}$ and consisted of an isocratic programme as follows: acetonitrile: $50 \mathrm{mM}$ ammonium acetate $(3: 1, \mathrm{v} / \mathrm{v}), \mathrm{pH}$. The injection volume was $20 \mu$ l. CPA standard was supplied by Sigma (St. Louis, MO, USA). Linearity, limit of detection (LOD) and limit of quantification (LOQ) were determined as for aflatoxins, using six standard solutions of $100,50,20,10,1$ and $0.5 \mu \mathrm{g} \mathrm{ml}^{-1}$.

For the comparison of means of quantitative variables, samples were first tested for normal distribution by Shapiro-Wilk test (for $n<30$ ) or KolmogorovSmirnov test (for $n \geq 30$ ), and for homogeneity of variances by Levene's test. Whenever samples followed these criteria, variances were analysed by one-way ANOVA, and multiple comparisons between samples pairs were made by Bonferroni's test $(n<30)$ or by Tukey's test $(n \geq 30)$. When samples failed both premises, normality and homogeneity of variances, samples were analysed pairwise by the non-parametric Mann-Whitney test (Maroco 2003). In all cases, the mean differences were significant at $P<0.05$.

Morphological data as well as mycotoxigenic ability of the isolates included in this analysis are summarised in Table 2. Results shown for Aspergillus parasiticus B strain are the mean of all isolates listed in Table 1 . In general, A. parasiticus $\mathrm{B}$ strain does not markedly differ from the typical $A$. parasiticus strain or from the other A. parasiticus-like species (A. transmontanensis and $A$. sergii), at both macro- and micromorphological levels. The major difference is observed in YES medium where, contrary to the typical $A$. parasiticus, conidia are almost absent in B strain colonies. Also, B strain sclerotia on CYA are significantly smaller than those from 


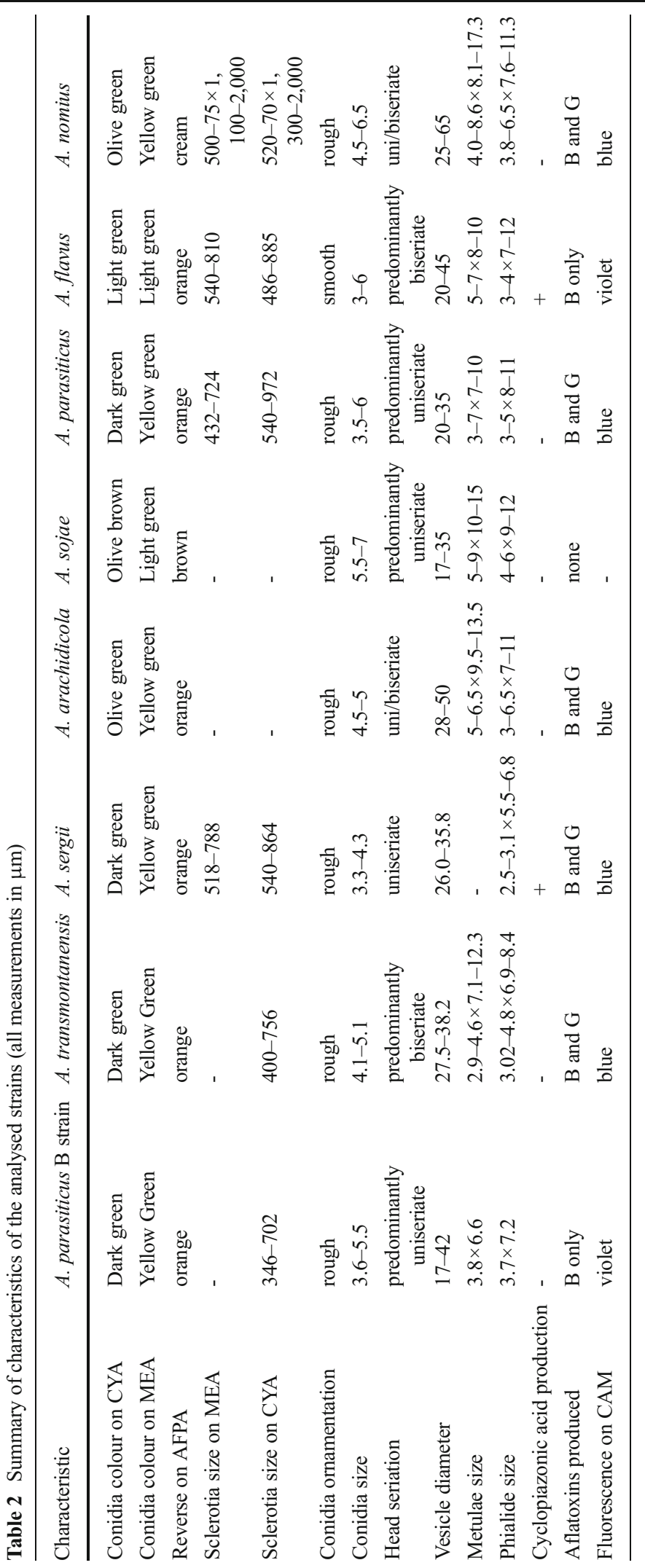


the other analysed species $(P<0.031)$. In terms of mycotoxin profile (aflatoxins and CPA), the B strain differs from all the other tested species (Table 2). $\mathrm{B}$ strain produces AFBs but not AFGs, an AF profile typical of A. flavus, and is a CPA nonproducer, like $A$. parasiticus.

Fungal growth on MEA and CYA at different temperatures is shown in Table 3. No growth occurred for any of the isolates at $5^{\circ} \mathrm{C}$. The B strain showed good growth at both 25 and $37^{\circ} \mathrm{C}$, but grew poorly at $42^{\circ} \mathrm{C}$, as did the remaining species. It grew better than A. parasiticus at $25^{\circ} \mathrm{C}$, and the opposite relation occurred at $37^{\circ} \mathrm{C}$, but with no significant difference $(P>0.05)$. There was also no significant difference $(P>0.05)$ between strain B and the other species for the three temperatures tested. At $42^{\circ} \mathrm{C}$, the atypical strain grew better than the typical A. parasiticus strain on MEA (but not on CYA), but not significantly $(P>0.05)$. At $42^{\circ} \mathrm{C}$, the atypical strain also grew better than the $A$. parasiticus-like species $A$. transmontanensis and $A$. sergii.

The effect of temperature on AF and CPA production is shown in Table 4 . The A parasiticus B strain, $A$. transmontanensis and $A$. sergii produce significantly more AFBs at $25^{\circ} \mathrm{C}$ than at $30^{\circ} \mathrm{C}$ or $37^{\circ} \mathrm{C}(P<0.05)$. On the other hand, A. parasiticus, $A$. nomius and $A$. arachidicola produce significantly more AFB1 at $30^{\circ} \mathrm{C}$ than at $25^{\circ} \mathrm{C}$ or $37^{\circ} \mathrm{C}(P=0)$. A. flavus produces only residual levels of AFB1, only detectable at $30^{\circ} \mathrm{C}$. At $37^{\circ} \mathrm{C}$, only $A$. arachidicola and $A$. nomius produce detectable amounts of AFB1 and AFG1.

In this study, we describe a fungal strain which is morphologically and genetically very closely related to A. parasiticus, but shows the distinctive feature of producing AFBs only. We have designated this atypical A. parasiticus strain as $A$. parasiticus $\mathrm{B}$ strain. To our knowledge, no other $A$. parasiticus strain has been described as producing AFBs only. Typical A. parasiticus strains are consistently reported as strongly aflatoxigenic, producing both AFBs and AFGs, and only few studies have reported very low proportions (3$6 \%$ ) of non-aflatoxigenic isolates within the species (Blaney et al. 1989; Doster et al. 1996; Horn et al. 1996; McAlpin et al. 1998; Tran-Dinh et al. 1999; Vaamonde et al. 2003). Contrary to A. flavus, $A$. parasiticus strains are also CPA non-producers, as is A. parasiticus $\mathrm{B}$ strain. Recently, two species closely related to $A$. parasiticus, $A$. transmontanensis and A. sergii, have been described (Soares et al. 2012), but the B strain is not similar to any of these species in its extrolite profile. Additional molecular (multilocus) analysis is needed to clarify the relation between this population and the typical $A$. parasiticus. Also, the analysis of key genes within the AF gene cluster would help to determine the reason for the atypical AF production ability.

The B strain seems to be better adapted to lower temperatures than the typical $A$. parasiticus strain, not only in terms of growth, but mostly in terms of aflatoxin production. A. parasiticus $\mathrm{B}$ strain, A. transmontanensis and $A$. sergii produce higher amounts of AFBs at $25^{\circ} \mathrm{C}$ than at $30^{\circ} \mathrm{C}$, whereas $A$. parasiticus, $A$. arachidicola, A. nomius and $A$. flavus produce higher amounts of AFs at $30^{\circ} \mathrm{C}$.

To our knowledge, the isolation of the B strain from Portuguese almond orchards represents the first report of this atypical $A$. parasiticus strain not producing AFGs. The typical strain of $A$. parasiticus has been

Table 3 Colony diameter on MEA and CYA, at three different temperatures (in $\mathrm{cm}$, mean $\pm \mathrm{SD}, n=3$ )

\begin{tabular}{|c|c|c|c|c|c|c|c|c|}
\hline & \multicolumn{4}{|l|}{ MEA } & \multicolumn{4}{|l|}{ CYA } \\
\hline & $42^{\circ} \mathrm{C}$ & $37^{\circ} \mathrm{C}$ & $25^{\circ} \mathrm{C}$ & $15^{\circ} \mathrm{C}$ & $42^{\circ} \mathrm{C}$ & $37^{\circ} \mathrm{C}$ & $25^{\circ} \mathrm{C}$ & $15^{\circ} \mathrm{C}$ \\
\hline A. parasiticus. B strain & $2.3 \pm 0.29$ & $6.9 \pm 0.17$ & $6.6 \pm 0.23$ & $3.2 \pm 0.08$ & $2.6 \pm 0.23$ & $6.7 \pm 0.36$ & $6.7 \pm 0.24$ & $3.2 \pm 0.05$ \\
\hline A. transmontanensis & $1.6 \pm 0.12$ & $5.2 \pm 0.06$ & $5.7 \pm 0.21$ & $3.1 \pm 0.06$ & $2.2 \pm 0.29$ & $6.6 \pm 0.17$ & $6.7 \pm 0.06$ & $3.2 \pm 0.06$ \\
\hline A. sergii & $1.4 \pm 0.35$ & $6.2 \pm 0.25$ & $6.3 \pm 0.58$ & $2.8 \pm 0.12$ & $2.1 \pm 0.23$ & $>7.0$ & $6.6 \pm 0.15$ & $2.9 \pm 0.25$ \\
\hline A. arachidicola & $2.0 \pm 0.15$ & $6.1 \pm 0.31$ & $5.8 \pm 0.12$ & $2.6 \pm 0.1$ & $2.5 \pm 0.21$ & $>7.0$ & $6.7 \pm 0.17$ & $2.5 \pm 0.06$ \\
\hline A. sojae & $2.1 \pm 0.15$ & $>7.0$ & $5.6 \pm 0.31$ & $3.0 \pm 0.15$ & $2.4 \pm 0.45$ & $6.1 \pm 0.15$ & $6.4 \pm 0.15$ & $2.6 \pm 0.35$ \\
\hline A. parasiticus & $1.8 \pm 0.21$ & $>7.0$ & $6.3 \pm 0.06$ & $3.0 \pm 0.1$ & $3.2 \pm 0.23$ & $6.9 \pm 0.12$ & $6.4 \pm 0.15$ & $3.0 \pm 0.23$ \\
\hline A. flavus & $2.5 \pm 0.26$ & $>7.0$ & $6.7 \pm 0.17$ & $1.1 \pm 0.1$ & $3.5 \pm 0.26$ & $>7.0$ & $6.9 \pm 0.17$ & $1.2 \pm 0.1$ \\
\hline A. nomius & $0.6 \pm 0.06$ & $>7.0$ & $>7.0$ & $2.2 \pm 0.21$ & $0.3 \pm 0.1$ & $>7.0$ & $>7.0$ & $2.3 \pm 0.25$ \\
\hline
\end{tabular}




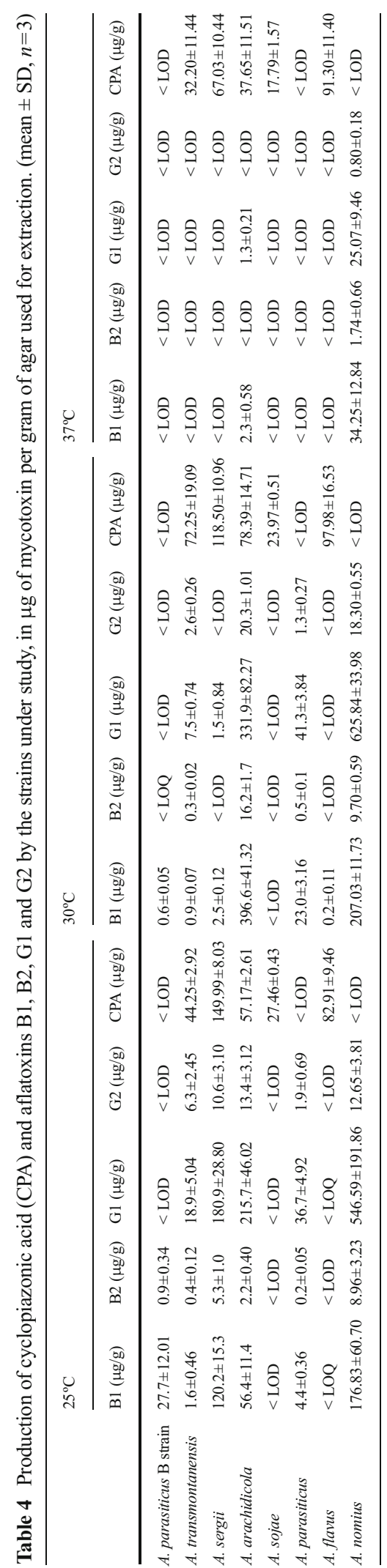

found to be the prevalent species among Aspergillus section Flavi in Portuguese almonds (Rodrigues et al. 2011), whereas studies from other regions of the world report only residual figures for this species in almonds and other nuts (e.g. Bayman et al. 2002; Baquião et al. 2013).

Fungal growth and mycotoxin production only occur under favourable conditions, which vary for each species depending on adaptability. Food intrinsic parameters associated to extrinsic factors are responsible for the spectrum of contaminating and dominating mycobiota. This is mostly related to the physiology of fungi and their adaptation to the different matrices and environmental conditions. The atypical $A$. parasiticus $\mathrm{B}$ strain herein described is of major interest due to the distinguishing physiological characteristic of producing larger amounts of AFB 1 at $25^{\circ} \mathrm{C}$ than the typical strain. This strain can become a major food safety concern in colder regions where the typical $A$. parasiticus strains are not well adapted.

Acknowledgments The authors thank the Project "BioInd Biotechnology and Bioengineering for improved Industrial and Agro-Food processes, REF. NORTE-07-0124-FEDER-000028" Co-funded by the Programa Operacional Regional do Norte (ON.2 - O Novo Norte), QREN, FEDER. The authors thank the FCT Strategic Projects PEst-OE/EQB/LA0023/2013 and PEst-. OE/AGR/UI0690/2011.

\section{References}

Baquião, A. C., de Oliveira, M. M. M., Reis, T. A., Zorzete, P., Atayde, D. D., \& Correa, B. (2013). Polyphasic approach to the identification of aspergillus section flavi isolated from brazil nuts. Food Chemistry, 139, 1127-1132.

Bayman, P., Baker, J. L., \& Mahoney, N. E. (2002). Aspergillus on tree nuts: incidence and associations. Mycopathologia, 155, 161-169.

Bennett, J. W., \& Klich, M. (2003). Mycotoxins. Clinical Microbiology Reviews, 16, 497-516.

Blaney, B. J., Kelly, M. A., Tyler, A. L., \& Connole, M. D. (1989). Aflatoxin and cyclopiazonic acid production by Queensland isolates of aspergillus flavus and aspergillus parasiticus. Australian Journal of Agricultural Research, 40, 395-400.

Bragulat, M. R., Abarca, M. L., \& Cabañes, F. J. (2001). An easy screening method for fungi producing ochratoxin A in pure culture. International Journal of Food Microbiology, 71, 139-144.

Cotty, P. J., \& Cardwell, K. F. (1999). Divergence of West African and North American communities of Aspergillus section Flavi. Applied and Environmental Microbiology, 65, 2264-2266. 
Doster, M. A., Michailides, T. J., \& Morgan, D. P. (1996). Aspergillus species and mycotoxins in figs from California orchards. Plant Disease, 80, 484-489.

Frisvad, J. C., Thrane, U., Samson, R. A., \& Pitt, J. I. (2006). Important mycotoxins and the fungi which produce them. In A. D. Hocking, J. I. Pitt, R. A. Samson, \& U. Thrane (Eds.), Advances in Food Mycology (pp. 3-31). New York: Springer.

Gqaleni, N., Smith, J. E., Lacey, J., \& Gettinby, G. (1997). Effects of temperature, water activity, and incubation time on production of aflatoxins and cyclopiazonic acid by an isolate of Aspergillus flavus in surface agar culture. Applied and Environmental Microbiology, 63, 1048-1053.

Horn, B. W. (2005). Colonization of wounded peanut seeds by soil fungi: Selectivity for species from Aspergillus section Flavi. Mycologia, 97, 202-217.

Horn, B. W. (2007). Biodiversity of Aspergillus section Flavi in the United States: A review. Food Additives and Contaminants, 24, 1088-1101.

Horn, B. W., Greene, R. L., Sobolev, V. S., Dorner, J. W., \& Powell, J. H. (1996). Association of morphology and mycotoxin production with vegetative compatibility groups in Aspergillus flavus, A. parasiticus, and A. tamarii. Mycologia, 88, 574-87.

Klich, M. A., \& Pitt, J. L. (1988). Differentiation of Aspergilus flavus and A. parasiticus and other closely related species. Transactions of the British Mycological Society, 91, 99-108.

Klich, M. A. (2002). Identification of common Aspergillus species. Wageningen: CBS.

Kurtzman, C. P., Horn, B. W., \& Hesseltine, C. W. (1987). Aspergillus nomius, a new aflatoxin-producing species related to Aspergillus flavus and Aspergillus tamarii. Antonie van Leeuwenhoek, 53, 147-158.

Maroco, J. (2003). Análise Estatística - Com utilização do SPSS (2nd ed.). Lisbon: Edições Sílabo, Lda.

McAlpin, C. E., Wiclow, D. T., \& Platis, C. E. (1998). Genotypic diversity of Aspergillus parasiticus in an Illinois corn field. Plant Disease, 82, 1132-1136.
Pildain, M. B., Frisvad, J. C., Vaamonde, G., Cabral, D., Varga, J., \& Samson, R. A. (2008). Two novel aflatoxin-producing Aspergillus species from Argentinean peanuts. International Journal of Systematic and Evolutionary Microbiology, 58, 725-735.

Rodrigues, P., Venâncio, A., Kozakiewicz, Z., \& Lima, N. (2009). A polyphasic approach to the identification of aflatoxigenic and non-aflatoxigenic strains of Aspergillus Section Flavi isolated from Portuguese almonds. International Journal of Food Microbiology, 129, 187-193.

Rodrigues, P., Santos, C., Venâncio, A., \& Lima, N. (2011). Species identification of Aspergillus section Flavi isolates from Portuguese almonds using phenotypic, including MALDI-TOF ICMS, and molecular approaches. Journal of Applied Microbiology, 111, 877-892.

Samson, R. A., Hoekstra, E. S., Lund, O., Filtenborg, O., \& Frisvad, J. C. (2004). Methods for the detection, isolation and characterisation of food-borne fungi. In R. A. Samson, E. S. Hoekstra, \& J. C. Frisvad (Eds.), Introduction to Food- and Airborne Fungi (pp. 283-305). Wageningen: CBS.

Soares, C., Rodrigues, P., Peterson, S., Lima, N., \& Venâncio, A. (2012). Three new species of Aspergillus section Flavi isolated from almonds and maize in Portugal. Mycologia, 104, 682-697.

Taverniers, I., de Loose, M., \& van Bockstaele, E. (2004). Trends in quality in the analytical laboratory. II. Analytical method validation and quality assurance. Trends in Analytical Chemistry, 23, 535-552.

Tran-Dinh, N., Pitt, J. I., \& Carter, D. A. (1999). Molecular genotype analysis of natural toxigenic and nontoxigenic isolates of Aspergillus flavus and A. parasiticus. Mycological Research, 103, 1485-1490.

Vaamonde, G., Patriarca, A., Pinto, V. F., Comeria, R., \& Degrossi, C. (2003). Variability of aflatoxin and cyclopiazonic acid production by Aspergillus section Flavi from different substrates in Argentina. International Journal of Food Microbiology, 88, 79-84. 